\title{
¿Capital económico o cultural? El efecto del origen social sobre las desventajas académicas de los hijos de inmigrantes en España*
}

\author{
Alberto Álvarez-Sotomayor \\ Universidad de Córdoba \\ aasotomayor@uco.es \\ Gloria Martínez-Cousinou \\ Universidad Loyola Andalucía \\ gmartinez@uloyola.es
}

Recibido: 24-02-2015

Aceptado: 09-05-2016

\section{Resumen}

Tanto la literatura internacional como la centrada en el caso español muestran que el origen social es el factor que más influye en el habitual rendimiento académico inferior de los hijos de inmigrantes. Menos evidencias hay acerca del mecanismo o de los mecanismos que explican dicha relación. En España, estas evidencias tienen como principal limitación el hecho de no diferenciar el origen nacional o étnico de los hijos de inmigrantes. El presente trabajo arroja luz sobre esta cuestión a través de un estudio de caso. Con datos de una encuesta realizada al alumnado de tercero y cuarto de ESO de los institutos de enseñanza secundaria de Marbella, se miden las desigualdades de rendimiento entre los distintos grupos de inmigrantes y los autóctonos, además de determinar en qué medida estas responden a cada uno de los dos mecanismos explicativos del origen social más referidos en la literatura sociológica: el nivel económico y el capital cultural. Los resultados de los análisis de regresión dan soporte empírico a ambos, pero otorgan un mayor peso explicativo al segundo. Asimismo, se evidencia que los modos y el grado en los que ambos mecanismos explican estas desventajas académicas varían sustancialmente entre los distintos grupos de origen nacional o geográfico, debido a la diferente composición de estos respecto a las variables económicas y socioculturales consideradas.

Palabras clave: rendimiento académico; estudiantes inmigrantes; integración socioeducativa; origen socioeconómico; capital cultural

* Los autores agradecen las sugerencias y los comentarios de los evaluadores anónimos que revisaron la primera versión de este trabajo y que, con ello, han contribuido a la mejora del mismo. 
Abstract. Financial or Cultural Capital? The Effect of Social Origin on Educational Disadvantage Among Children of Immigrants in Spain

Both the international and national literature have shown that social background is the most influential social factor in determining the consistently lower educational outcomes of children of immigrants compared to that of natives. However, less is known about the specific mechanisms that contribute to explain this relationship. Previous studies carried out in Spain lack an empirical distinction based on the ethnic origin of the children of immigrants. This study sheds light on this issue through a case study design. Using data from a survey conducted among students in the last two years of compulsory education in Marbella, this paper measures the inequalities in educational outcomes between immigrants and native students. This is done with the aim of clarifying to what extent such inequalities are explained by each of the two main social origin mechanisms found in the specialized literature: financial capital and cultural capital. The results of the regression analysis provide empirical support for both types of mechanisms, although the latter is found to have stronger explanatory power. Moreover, the way and the extent to which both mechanisms explain academic inequalities vary substantially from one ethnic origin to another due to compositional differences regarding the economic and sociocultural variables analyzed.

Keywords: educational outcomes; immigrant students; socio-educational integration; socioeconomic background; cultural capital

\begin{aligned} & \multicolumn{2}{c}{ Sumario } \\ & 1. Introducción 5. Conclusiones \\ & 2. Marco teórico e hipótesis Referencias bibliográficas \\ & 3. Metodología Anexo \\ & 4. Resultados \end{aligned}

\section{Introducción}

El análisis de la relación entre origen social (o socioeconómico) y rendimiento educativo está amplia y fuertemente asentado dentro de la investigación sociológica, tanto en el nivel empírico como en el teórico. En el ámbito internacional (Breen y Jonsson, 2005) y en el caso concreto de España (Carabaña, 1999; Martínez García, 2002; Manzano, 2001; Mediavilla y Calero, 2009), las evidencias demuestran consistentemente, desde la década de 1960, la existencia de una fuerte asociación positiva entre estas dos variables. Menos cerrada está la cuestión sobre cómo se explica dicha asociación o, en otras palabras, sobre el principal mecanismo que operaría entre ambas variables. Desde la sociología, dos son los enfoques teóricos que acaparan la mayor parte del debate (De Graff et al., 2000; Martínez García, 2011): uno que, desde el individualismo metodológico y partiendo del trabajo de Boudon (1974), pone el énfasis en las desigualdades respecto a la posición económica de la familia y otro que, desde 
la sociología crítica de la educación de Bourdieu y Passeron (2008), se centra en desigualdades de carácter sociocultural.

El análisis del efecto que tiene el origen social sobre el rendimiento educativo resulta igualmente relevante para el estudio de los resultados de los alumnos de origen inmigrante, objeto concreto de este trabajo. De hecho, en esta materia es una práctica habitual que, una vez medido el rendimiento diferencial de este alumnado respecto al nativo, uno de los primeros pasos analíticos consista en examinar el efecto que tiene el origen social sobre las diferencias halladas (Heath y Brinbaum, 2007). Mediante técnicas multivariables se analiza qué porción de la varianza en los resultados académicos es consecuencia de las desigualdades en el origen social entre las familias de los distintos grupos de inmigrantes y las de los nativos. Las implicaciones de los resultados serán de gran relevancia, pues en la medida en que el origen social sea más responsable, menos lo serán factores estrictamente vinculados al origen nacional, "étnico» o migratorio de estos alumnos, con las importantes implicaciones prácticas que ello pueda conllevar.

A este respecto, las evidencias disponibles en la literatura internacional suelen señalar que el origen social es el factor explicativo de mayor peso en el diferencial académico entre estudiantes inmigrantes y nativos (Heath et al., 2008; Kao y Thompson, 2003; Schnepf, 2008), si bien el porcentaje de varianza que explica difiere sustancialmente de unos países a otros (Heath et al., 2008; Levels et al., 2008; Stanat y Christensen, 2006; OECD, 2011). En cuanto a los mecanismos explicativos apuntados, son minoría los trabajos que los exploran conjuntamente. Ello es debido, en parte, al uso extendido de índices socioeconómicos que buscan explicaciones más parsimoniosas ${ }^{1}$. No obstante, aquellos que lo hacen encuentran resultados que apoyan parcialmente a los dos enfoques teóricos mencionados (Cebolla-Boado, 2008).

Respecto al conocimiento acumulado en España, se parte, en primer lugar, de la consideración de que, como ocurre en la mayoría de contextos analizados, el alumnado de origen inmigrante se halla en desventaja académica. Además de los datos del PISA (Calero et al., 2009; Stanat y Christensen, 2006; OECD, 2011), que mediante pruebas estandarizadas mide competencias en lectura, matemáticas y ciencias en estudiantes de 15 años, las evidencias provienen de distintos tipos de indicadores: tasas de abandono en secundaria o en la etapa postobligatoria (Aparicio y Tornos, 2006; Fullana et al., 2003; Serra y Palaudàrias, 2008), dificultades en el aprendizaje al finalizar primaria (Fullana et al., 2003), pruebas de diagnóstico en primaria (Cebolla-Boado y Garrido, 2008) o la llamada "tasa de idoneidad $»^{2}$ (Defensor del Pueblo, 2003).

Si bien estos trabajos suponen un progreso sustancial en el conocimiento del rendimiento de dicho alumnado, aún hay terreno por avanzar. Seguramente, lo más significativo sea la todavía escasa evidencia respecto a cómo se

1. Por ejemplo, el SES (índice de estatus socioeconómico generalizado en la tradición estadounidense) o el ESCS (índice de estatus económico, social y cultural) creado para PISA.

2. Porcentaje de alumnos que tienen la edad correspondiente al curso en el que se encuentran. 
jerarquizan esas diferencias en función del origen nacional de los estudiantes, una cuestión capital a tenor de las importantes variaciones que suelen registrarse en torno a esta variable (Heath et al., 2008; Kao y Thompson, 2003). El hecho de que, en España, PISA no contenga información sobre el origen nacional resulta un importante hándicap en este sentido, ya que esta laguna apenas ha sido cubierta por investigaciones que hayan generado otras fuentes de datos. Las pruebas de diagnóstico realizadas por el Instituto Nacional de Evaluación y Calidad del Sistema Educativo en primaria en 2003 constituyen una de las pocas excepciones relevantes. En sus datos, los africanos y los latinoamericanos eran los que presentaban un rendimiento más bajo respecto a los nativos españoles, mientras que los europeos y los asiáticos mostraban una desventaja menor (Cebolla-Boado y Garrido, 2008).

En segundo lugar, en relación con el estudio en España del efecto que tiene el origen social sobre los resultados académicos de los inmigrantes, este se ha desarrollado fundamentalmente en el último decenio. Ha sido a partir de los datos de PISA 2003 y ediciones sucesivas, que han servido como fuente para los escasos trabajos que han abordado esta cuestión. Así, por ejemplo, los análisis de Calero et al. (2009) y de Zinovyeva et al. (2014) encuentran que el origen social daría cuenta de una parte importante de la brecha que hay entre estudiantes inmigrantes y nativos en España, aproximadamente de la mitad, según halla el segundo de estos trabajos. Y en Andalucía, la primera generación ve reducida su desventaja alrededor de un $40 \%$ cuando el origen social es tenido en cuenta, según se obtiene de una explotación de la submuestra de dicha comunidad (Álvarez-Sotomayor et al., 2015). Estos trabajos encuentran efectos significativos tanto de las variables (socio)económicas introducidas en los modelos, como de las socioculturales. Ello indicaría que sendos mecanismos explicativos señalados por los dos enfoques sociológicos anteriormente destacados estarían operando conjuntamente. Desafortunadamente, el ya mencionado hándicap de los datos de PISA impide conocer si el efecto del origen social a través de estos dos mecanismos varía para los distintos grupos nacionales o de procedencia extranjera.

Teniendo en cuenta lo anterior, con este trabajo se pretende contribuir modestamente a avanzar en las lagunas empíricas señaladas para el contexto español. Para ello se establece como primer objetivo necesario medir el rendimiento académico diferencial del alumnado inmigrante respecto al nativo, distinguiendo el origen nacional o geográfico de dicho alumnado. De este modo se aporta un nuevo caso empírico al "mapa» español sobre la situación académica de los hijos de inmigrantes en España. Se hace, además, a través de un indicador poco empleado previamente en el marco de este país: las calificaciones obtenidas en las asignaturas curriculares cursadas.

Una vez medido ese diferencial académico, se estará en disposición de abordar los dos objetivos principales de este trabajo, a saber: (1) conocer qué proporción de las desigualdades halladas entre unos grupos y otros es fruto de diferencias relativas al origen socioeconómico y, sobre todo, (2) descubrir el modo o los modos por los que dicho factor explica tales desigualdades, es 
decir, revelar cuál o cuáles son los mecanismos a través de los que opera. Para esto último se contrastará la validez empírica de los dos enfoques teóricos con mayor peso en la literatura sociológica, que se identificarán aquí como tesis de la desigualdad económica y tesis de la desigualdad sociocultural, respectivamente. Todo ello se llevará a cabo tomando los institutos de secundaria del municipio de Marbella como caso de estudio. El hecho de que otro tipo de variables de interés - por ejemplo, las vinculadas al origen étnico o nacional (tiempo de residencia, dominio del español y otros factores culturales) o al contexto escolar - no sean incorporadas a estos análisis no implica ni mucho menos la desconsideración de las mismas. Responde, simplemente, a que son otros los objetivos de este trabajo.

La estructura del artículo es la que sigue. En primer lugar, se resumen los principales argumentos teóricos de los dos enfoques mencionados y se formulan las hipótesis a contrastar que se derivan de cada uno de ellos. En segundo lugar, se detallan los aspectos de mayor interés acerca de los datos explotados y de la metodología empleada. En tercer lugar, se discuten los principales resultados empíricos, centrándonos inicialmente en el grado en que el rendimiento de los estudiantes inmigrantes se distancia del de los nativos, y examinando después el efecto de cada uno de los dos mecanismos explicativos fundamentales considerados. Por último, se concluye sintetizando los resultados principales, poniéndolos en relación con la literatura y planteando algunas reflexiones sobre las implicaciones que pueden tener en términos de política educativa.

\section{Marco teórico e hipótesis}

\subsection{La tesis de la desigualdad económica}

La constricción económica constituye probablemente la explicación más evidente entre aquellas que ven en el origen social la causa de las desigualdades educativas. Es obvio que las familias con menos recursos monetarios tendrán más dificultades para pagar los costes de la educación de sus hijos, lo que restringirá las posibilidades académicas de estos. En la literatura sociológica esta tesis ha sido defendida mediante modelos teóricos posicionados en el individualismo metodológico de la elección racional (Boudon, 1974; Breen y Goldthorpe, 1997; Erikson y Jonsson, 1996). Desde este enfoque se afirma que las familias deciden cuánto invierten en la educación de sus hijos después de realizar un análisis de costes y beneficios, y por más que los beneficios de la educación pudieran ser similares para todos, los recursos de cada familia no lo son, lo que hará que las decisiones a ese respecto sean distintas (Boudon, 1974). Así, las desigualdades educativas se originan debido, fundamentalmente, a la diferente distribución de recursos económicos de los hogares y a los costes de oportunidad de estudiar, siendo las inversiones que se realizan en educación decisiones económicamente racionales.

A priori, puede pensarse que la tesis de la constricción económica perderá fuerza en casos empíricos como el que aquí nos ocupa, donde el 
llustración 1. Relación entre origen social y los resultados educativos según la tesis de la constricción económica

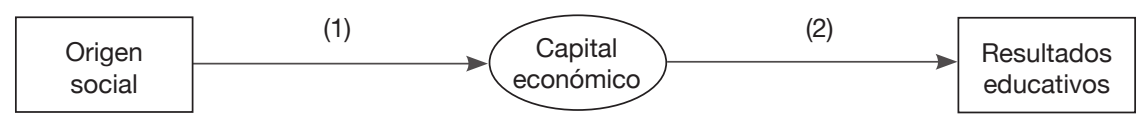

Fuente: elaboración propia.

alumnado accede a la educación secundaria gratuitamente. Sin embargo, la universalidad de esta etapa no hace de ella un espacio libre de competencia económica, ya que los padres y las madres también han de afrontar costes indirectos de la educación (material escolar, transporte, clases privadas, etc.) (Lucas, 2001).

Por lo tanto, desde este planteamiento las desigualdades educativas debidas al origen social se explican por las diferencias que este genera en cuanto a la disponibilidad de recursos económicos (ilustración 1).

En consecuencia, en la medida en que los hijos de inmigrantes se encuentren comparativamente en desventaja respecto al nivel económico de sus familias, este estaría contribuyendo negativamente a su rendimiento académico diferencial frente al alumnado nativo, mientras que si su situación fuera de ventaja ocurriría lo opuesto. Según evidencia la literatura, en España (Bernardi et al., 2011) y en Andalucía (Rinken et al., 2010) los inmigrantes que proceden de países menos desarrollados presentan más riesgo de desempleo, se concentran en mayor medida en las categorías profesionales no cualificadas y ocupan las posiciones más bajas dentro de la estructura social del mercado de trabajo. En contraste, los europeos occidentales presentan mejores condiciones de participación en el mercado laboral español que las de la mayoría de los demás inmigrantes e incluso que las de los propios autóctonos (Kuehn, 2009). Teniendo en cuenta esta circunstancia, se establece la siguiente hipótesis de investigación:

$\mathrm{H}_{1}$ : el efecto del origen social sobre el desigual rendimiento educativo del alumnado inmigrante respecto al nativo se explica por la distribución desigual de recursos financieros entre las familias de unos y otros.

\subsection{La tesis de la desigualdad sociocultural ("capital cultural»)}

El estudio de la importancia que puede tener el origen sociocultural del niño (aquel que hereda de la familia) a la hora de explicar las diferencias en los resultados educativos obtenidos va inexorablemente unido a la obra de Pierre Bourdieu. Para Bourdieu (1980), las clases sociales no solo implican desigualdad en la posesión de recursos económicos, sino también en las formas de pensar, de sentir y de actuar (habitus). En la escuela, los distintos habitus de los estudiantes les distinguen en cuanto al «capital cultural» con el que llegan 
llustración 2. Relación entre origen social y logro educativo según la teoría de la reproducción cultural

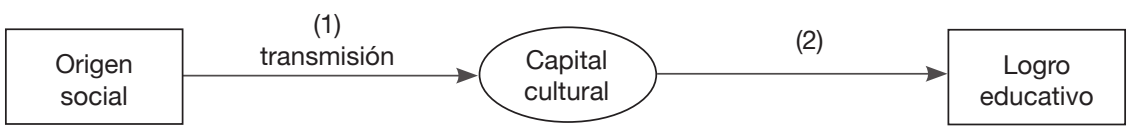

Fuente: elaboración propia.

a esta, es decir, en cuanto a los estilos, los gustos, los hábitos y las disposiciones culturales que les son transmitidos en el seno de su familia.

Este tipo de capital puede presentarse, según Bourdieu (1986), bajo tres formas o estados diferentes: el incorporado, el menos tangible y más simbólico de los tres, cuya acumulación requiere de un lento proceso de adopción al que Bourdieu suele referirse a través del término inculcación — similar al de socialización-; el objetivado (cosificado), que se manifiesta a través de bienes culturales como esculturas, cuadros, libros, álbumes de música, etc. y que es fácilmente mutable en dinero, y el institucionalizado, por ser institucionalmente reconocido a través, por ejemplo, de certificaciones académicas mediante las cuales el agente que las emite acredita la competencia cultural del titular de las mismas.

La explicación del papel que desempeña el capital cultural como factor condicionante de las desigualdades educativas es desarrollada por Bourdieu y Passeron (2008) en su conocida teoría de la reproducción cultural y social. Según esta teoría, la explicación del logro educativo desigual que existía entre las clases sociales residía en que, mientras el capital cultural de las clases más bajas era desvalorado y despreciado por el sistema educativo, el de las clases medias y altas era reforzado y promovido. Así pues, el capital cultural socialmente más valorado (el «dominante»), el cual es más probable que aparezca entre los núcleos de mayor nivel socioeconómico, por transmitirse en el seno de la familia (vector 1, ilustración 2), es, al mismo tiempo, aquel que es apreciado en la escuela, lo que provoca que el niño de clase social alta tenga mayor probabilidad de alcanzar el éxito académico (vector 2, ilustración 2).

El efecto del capital cultural sobre los resultados educativos ha sido ampliamente contrastado; no tanto en el análisis de desigualdades entre inmigrantes y nativos, donde las evidencias son relativamente escasas, como, sobre todo, en el análisis de las desigualdades de clase en general ${ }^{3}$. Eso no evita que tanto el concepto como el mecanismo sugerido por Bourdieu y Passeron hayan sido objeto de importantes críticas (Kingston, 2001; Sullivan, 2001). Una de las más relevantes para los intereses de este trabajo proviene de una corriente de estudios que mantiene que la asociación entre capital cultural y logro educativo (vector 2, ilustración 2) no sería atribuible al mecanismo causal defendido por Bourdieu, sino más bien a que algunos de los recursos y de

3. Ver Lareau y Weininger (2003) y Jæger (2009) para revisiones de la literatura correspondiente. 
las formas de participación cultural operacionalizados como capital cultural estimulan el desarrollo de habilidades, disposiciones o funciones cognitivas que ayudan a los alumnos a desenvolverse mejor académicamente (Crook, 1997; De Graff et al., 2000; Katz et al., 1993; Sullivan, 2001).

De cualquier modo, tanto desde la postura bourdiana como desde esta última, se defiende que habría factores de carácter sociocultural que mediarían entre el origen social y el rendimiento educativo de estos, siendo, pues, un potencial elemento explicativo de las desigualdades en este ámbito. Por lo tanto, aplicado al tipo de desigualdad que aquí se analiza, puede hipotetizarse lo siguiente:

$\mathrm{H}_{2}$ : el efecto del origen social sobre el rendimiento educativo desigual del alumnado inmigrante respecto al nativo se explica por las diferencias en el capital cultural de las familias de unos y otros.

\section{Metodología}

\subsection{Método y datos}

Este trabajo parte de un estudio de caso más amplio acerca de los factores que afectan al rendimiento académico diferencial de los hijos de inmigrantes ${ }^{4}$. En él se combinaron técnicas cuantitativas y cualitativas de recogida y análisis de datos, si bien para los objetivos de este artículo se explotan únicamente los datos cuantitativos. Estos últimos proceden de una encuesta cumplimentada por los propios estudiantes ${ }^{5}$ durante una hora lectiva del último trimestre del curso 2006-2007 y se dirigió a todos los alumnos de tercero y cuarto de ESO de los diez institutos públicos del municipio de Marbella $(n=1.461)$. De ellos, el 29,3\% (426) está formado por estudiantes de origen inmigrante, definidos, siguiendo la postura más extendida en la literatura especializada, como aquellos con al menos uno de los padres nacido en el extranjero. El resto (1.035) es alumnado de origen nativo.

La elección del municipio de Marbella como caso de estudio relevante dentro de la comunidad autónoma de Andalucía se basó en tres criterios apriorísticos:

1. La existencia de una elevada proporción de alumnado extranjero matriculado en enseñanza secundaria, etapa educativa objeto de análisis. Según datos de la Consejería de Educación de la Junta de Andalucía (2007), en la fecha del estudio Málaga era la provincia andaluza con mayor volumen

4. Véase Álvarez de Sotomayor (2011).

5. Se toma la declaración de los alumnos como fuente para conocer sus propios resultados escolares una vez comprobada la imposibilidad de contar directamente con sus calificaciones oficiales por motivos de tipo legal y administrativo. En cualquier caso, esta se ha mostrado repetidamente como una fuente razonablemente fiable, pues correlaciona altamente con los resultados recogidos en los registros oficiales (Kuncel et al., 2005). 
de alumnado extranjero, con 27.352 estudiantes matriculados en el curso 2006-2007 en todas las enseñanzas no universitarias. De ellos, 8.210 se encontraban cursando la ESO. Además, según datos del Anuario Estadístico de Inmigración (Ministerio de Empleo y Seguridad Social, 2008), se trataba de la provincia andaluza donde residían más menores de 16 años extranjeros (17.975) y donde había más nacidos de madre y/o padre foráneo $(4.048)^{6}$. Descendiendo al nivel municipal, los datos del padrón de habitantes de 2007 situaban a Marbella como el segundo municipio de toda Andalucía en cuanto a número total de extranjeros (29.963). Esto suponía un $24 \%$ de extranjeros sobre el total de población residente en el municipio (126.422 habitantes) ${ }^{7}$. Es decir, la concentración de población extranjera en Marbella se situaba muy por encima de la concentración existente en la provincia de Málaga (un 14\%), en el total de Andalucía (un 7\%) y en el total de España (un 10\%).

2. El hecho de que dicho alumnado extranjero estuviera geográficamente concentrado en un número reducido de centros de secundaria, de manera que se pudiese analizar optimizando el tiempo y los costes de la investigación. Un criterio que se cumplía en el caso de Marbella, donde, aparte de una elevada concentración de extranjeros con carácter general, la existencia de diez institutos de secundaria permitía analizar de forma eficiente el rendimiento académico de estos con respecto a los nativos.

3. La existencia de diversidad en el origen nacional de tales alumnos extranjeros. En este sentido, se tuvo en cuenta la previsible composición mixta de los estudiantes en cuanto a su procedencia a tenor de los datos del padrón antes citados. Algo que se confirmó, al igual que los dos apartados anteriores, una vez que se analizó en profundidad el caso marbellí.

En cuanto a la etapa de enseñanza analizada (segundo ciclo de la ESO), su elección responde al hecho de que esta es la fase inmediatamente anterior al punto más crítico y definitorio de la que será la trayectoria educativa final del individuo, aquel en el que ha de optar entre no continuar los estudios para acceder directamente al mercado laboral, realizar algún módulo de formación profesional o cursar el bachillerato y tomar así el camino más orientado a la universidad.

Es importante poner en valor que la encuesta realizada para este análisis no recoge, como suele ser habitual, una muestra poblacional, sino que contempla el conjunto del universo a estudiar (todos los alumnos matriculados en el último ciclo de la ESO en los centros públicos de Marbella). Los únicos estudiantes que no completaron el cuestionario fueron los que no acudieron a clase

6. Desde 2009, el Anuario Estadístico de Inmigración no incluye la información desagregada por provincias sobre residentes extranjeros menores de 16 años ni sobre nacidos de padre y/o madre extranjeros.

7. La estadística de enseñanzas no universitarias no ofrece sus datos desagregados por municipios, de ahí que se utilizasen los del padrón, junto con los de alumnado extranjero en el nivel provincial, como indicativos para la elección del municipio. 
durante la hora lectiva en la que se llevó a cabo la encuesta ${ }^{8}$. Por tanto, en lugar de una muestra, contamos aquí con el censo de la población objeto de estudio, lo cual invalida la necesidad y el sentido de realizar inferencias estadísticas.

\subsection{Variables}

Como variables de rendimiento académico se emplean las siguientes: nota global (media, expresada de 1 a 10, del conjunto de calificaciones obtenidas en el último trimestre evaluado en el momento de realizar la encuesta); número de suspensos; número de sobresalientes; repetidores potenciales (contabiliza a aquellos que han suspendido más de dos asignaturas en el último trimestre evaluado y que, por tanto, tendrían que repetir curso en el caso hipotético de que esa hubiese sido la evaluación final) ${ }^{9}$, y tasa de idoneidad (porcentaje de alumnos que se encuentran en el curso que les corresponde por su edad ${ }^{10}$ ). Todas ellas se utilizarán en los análisis descriptivos que miden la distancia académica entre alumnado de origen inmigrante y alumnado nativo, mientras que, en los análisis multivariados necesarios para contrastar las dos hipótesis planteadas en el marco teórico, se tomará solo la nota global como variable dependiente. El motivo es que esta es la que mejor representa los resultados académicos, al ser la media de todas las calificaciones obtenidas por el estudiante ${ }^{11}$.

Conviene aclarar que, salvo la tasa de idoneidad, el resto de estas variables de rendimiento se basan en la declaración de los propios estudiantes. Se tomó esta decisión una vez comprobada la imposibilidad de contar directamente con sus calificaciones oficiales por motivos de carácter legal y administrativo. Por más que la declaración del alumnado no sea la manera óptima de medir sus resultados educativos, esta se ha mostrado fiable en repetidas ocasiones, al comprobarse que su correlación con los resultados oficiales suele ser muy alta, alcanzando a menudo valores de colinealidad (Cassady, 2001; Frucot y Cook, 1994; Goldman et al., 1990; Kuncel et al., 2005; Trice, 1990) ${ }^{12}$. Como variables independientes, se utilizan las siguientes.

8. Según las estimaciones más pesimistas, se habría encuestado a más del $70 \%$ del total de matriculados en tercero y cuarto de ESO en el periodo de realización de la encuesta.

9. En el momento de realizar la encuesta, un alumno de ESO podía pasar al curso siguiente con un máximo de dos asignaturas suspensas.

10. Las edades que se consideran «idóneas» para tercero de ESO son los 14 o 15 años; más concretamente, haber cumplido los 14 durante el año en el que el curso comienza (2006, en este caso) y los 15 en el que termina (2007), lo que aquí implicaba haber nacido en el año 1992. Para cuarto, las edades son 15 y 16 años, para lo cual debía haberse nacido en 1991.

11. Las preguntas de las que se extraen estas variables y el resto de las que se utilizan en el presente trabajo pueden consultarse en Álvarez de Sotomayor (2011:365), donde se encuentra disponible el cuestionario completo diseñado para este estudio. En concreto, las que dan lugar a las variables de rendimiento señaladas son las preguntas P.48 del citado cuestionario.

12. Seguramente, el estudio más completo sobre la validez y la fiabilidad de las calificaciones declaradas por los alumnos es el de Kuncel et al. (2005). En él, se realiza un metaanálisis que da como resultado una correlación de 0,84 entre las puntuaciones autodeclaradas y las oficiales para una muestra total de 56.265 estudiantes en EE. UU. No se han hallado análisis de este tipo en España. 
La $e d a d$, el curso (estar en tercero o en cuarto de ESO) y el sexo - de relevancia contrastada, dado el habitual mejor rendimiento académico general de las mujeres- se incluyen como variables de control en las regresiones efectuadas más adelante.

Como indicadores del nivel económico del hogar, se consideran las variables ISEI — definida como la puntuación más alta alcanzada por los padres en el International Socio-Economic Index of Occupational Status, un índice socioeconómico de uso muy extendido que mide el estatus ocupacional de los padres y que es aplicable a escala internacional (Ganzeboom et al., 1992) —, y nivel educativo de los padres (etapa de estudios más alta alcanzada entre los dos progenitores, codificada en la encuesta en seis categorías y recodificada para los análisis de este trabajo en tres: sin estudios o con estudios primarios, estudios secundarios y estudios universitarios).

Para medir el nivel sociocultural del hogar se consideran tres indicadores. Los dos primeros (clases culturales extraescolares y actividades culturales) responden en buen grado a la operacionalización predominante del capital cultural, que lo asimila a los gustos, a los consumos, a los hábitos y a los estilos propios de la llamada «alta cultura» (Lareau y Weininger, 2003). Las clases culturales extraescolares se miden a través de tres variables dicotómicas que recogen si se asiste regularmente a sesiones educativas de música, de otras artes (pintura, danza, fotografía, teatro, cine, etc.) o de idiomas fuera del horario lectivo. Las actividades culturales se miden por medio de tres variables que captan de 1 (nunca o casi nunca) a 5 (varias veces a la semana) la frecuencia con la que el estudiante realiza diversas actividades de carácter cultural (ir a museos, ir al teatro y tocar un instrumento musical) ${ }^{13}$, y dos variables sobre hábito lector (frecuencia con la que lee libros no relacionados con el instituto y afición por la lectura).

El tercer indicador del nivel sociocultural del hogar capta, mediante cinco variables dicotómicas, la disponibilidad en el hogar de diversos recursos educativos (un sitio tranquilo para estudiar, ordenador, diccionario, calculadora y más de 50 libros ${ }^{14}$. Se trata de un indicador de uso muy extendido para medir esta dimensión sociocultural ${ }^{15}$ y que se correspondería con aquello que Bourdieu identificaba como "capital cultural objetivado».

Además, todos los análisis incluyen la variable origen nacional o geográfico del estudiante. A este respecto, cabe advertir que, a efectos de los análisis

13. En la encuesta, se tuvieron en cuenta otras dos actividades culturales («frecuencia de asistencia a conciertos» $\mathrm{y}$ «frecuencia de asistencia al cine») que no han sido incluidas en los análisis por no resultar relevantes como variables independientes, al presentar correlaciones muy bajas con la variable dependiente «nota global».

14. En la encuesta, se tuvo en cuenta la disponibilidad en el hogar de otros tres recursos educativos (mesa de estudio, conexión a Internet y enciclopedia) que no han sido incluidos en los análisis por no resultar relevantes como variables independientes, al presentar correlaciones muy bajas con la variable dependiente nota global.

15. Ver, por ejemplo, Teachman (1987), Roscigno y Ainswoth-Darnell (1999) o diversos estudios internacionales (PISA, FISS, SISS, SIMS y TIMS). 
multivariables realizados en el segundo apartado de la sección de resultados, la distinción de los orígenes aquí empleada se hará en algunos casos respecto a categorías necesariamente más amplias que el origen nacional, que sería, sin duda, la categorización más apropiada. El motivo es evitar los problemas derivados de realizar análisis sobre subpoblaciones con un número de casos muy bajo $^{16}$. Por ello se lleva a cabo una clasificación del origen geográfico en la que los criterios de agrupamiento se construyen tanto en función del área geográfica como del tamaño de los grupos. Tal clasificación distingue a españoles de origen nativo (con los dos padres nacidos en España), a latinoamericanos (que suponen un $44 \%$ del alumnado inmigrante del caso estudiado), a europeos occidentales (un 25\%), a marroquíes (un 14\%) y a un grupo de alumnos de otros países menos desarrollados —otros APMED (alumnos de países menos desarrollados) - (un 14\%), compuesto en su mayor parte (en más de un 80\%) por oriundos de países de la Europa del Este (incluidos los países de la extinta Unión Soviética) y por un pequeño grupo de países asiáticos. Los alumnos inmigrantes cuyo origen no se encuadra en ninguno de estos cuatro grupos (aquellos que proceden de países altamente desarrollados más allá de la Europa occidental y un pequeño grupo de los que se desconoce su país de origen) son incluidos en una categoría residual (resto de inmigrantes) que supone solo el 4\% del conjunto y que, aunque queda recogida en los cuadros, no será analizada.

\section{Resultados}

\subsection{Las desventajas del alumnado inmigrante en el rendimiento académico}

El análisis de los primeros resultados descriptivos muestra la existencia de desigualdades tanto entre nativos e inmigrantes, como entre los distintos grupos de origen de los últimos. Los nativos son los que obtienen mejores calificaciones y, de media, todos los grupos de inmigrantes se encuentran en situación de desventaja académica (tabla 1). En los cruces por orígenes nacionales (tabla 2) la única excepción se detecta en los ucranianos, pero su mejor rendimiento se limita a la asignatura de matemáticas. Se confirma así el rendimiento académico inferior de los alumnos de origen inmigrante.

A grandes rasgos, la distinción de los principales grupos de origen que será utilizada en los análisis multivariados posteriores deja al grupo de otros APMED y a los europeos occidentales como los que obtienen mejores calificaciones en el último trimestre (por este orden, a asiáticos, europeos del Este y originarios de la Europa occidental, si se desglosa algo más el primero de ellos). El grupo de otros APMED se distancia de los nativos solamente en 0,22 puntos en

16. Problemas que, en este caso concreto, no serían de representatividad estadística (puesto que, como ya ha sido indicado, lo que se analiza no es una muestra aleatoria, es una encuesta sobre el conjunto de la población a estudiar), sino más bien de sentido común, ya que cualquier cosa que se diga sobre un número muy reducido de personas tendrá muy poco interés, porque puede deberse a características específicas de ese grupo, y precisamente porque aquí no han sido escogidas al azar, la probabilidad de que se parezcan entre sí aumentará. 
Tabla 1. Rendimiento académico de los alumnos según grupos de origen

\begin{tabular}{|c|c|c|c|c|c|c|c|c|}
\hline \multicolumn{2}{|c|}{ Resultados educativos } & \multirow{2}{*}{$\begin{array}{c}\text { Nativos } \\
6,06\end{array}$} & \multirow{2}{*}{$\begin{array}{r}\begin{array}{c}\text { Europa } \\
\text { occidental }\end{array} \\
5,75\end{array}$} & \multirow{2}{*}{$\begin{array}{c}\begin{array}{c}\text { América } \\
\text { Latina }\end{array} \\
5,65\end{array}$} & \multirow{2}{*}{$\begin{array}{c}\text { Marruecos } \\
5,39\end{array}$} & \multirow{2}{*}{$\begin{array}{c}\begin{array}{c}\text { Otros } \\
\text { APMED }\end{array} \\
5,84\end{array}$} & \multirow{2}{*}{$\begin{array}{c}\begin{array}{c}\text { Total } \\
\text { inmigrantes }\end{array} \\
5,68\end{array}$} & \multirow{2}{*}{$\begin{array}{r}\text { Total } \\
5,95 \\
\end{array}$} \\
\hline Nota global & Media & & & & & & & \\
\hline & Desv. típ. & 1,50 & 1,43 & 1,47 & 1,44 & 1,51 & 1,45 & 1,49 \\
\hline \multirow[t]{2}{*}{ N. ${ }^{\circ}$ de suspensos } & Media & 2,73 & 3,38 & 3,75 & 4,05 & 3,11 & 3,58 & 2,97 \\
\hline & Desv. típ. & 2,69 & 2,76 & 3,02 & 3,09 & 2,54 & 2,89 & 2,77 \\
\hline \multirow{2}{*}{$\begin{array}{l}\mathrm{N}^{\circ}{ }^{\circ} \text { de } \\
\text { sobresalientes }\end{array}$} & Media & 1,38 & 1,10 & 1,11 & 0,87 & 1,39 & 1,1 & 1,31 \\
\hline & Desv. típ. & 2,04 & 1,76 & 3,03 & 1,56 & 1,88 & 1,69 & 1,95 \\
\hline \multicolumn{2}{|c|}{ Repetidores potenciales (\%) } & 45,3 & 55,9 & 58,0 & 58,2 & 54,3 & 56,6 & 48,5 \\
\hline \multicolumn{2}{|l|}{ Tasa de idoneidad } & 71,14 & 62,86 & 60,22 & 60,34 & 62,07 & 62,21 & 68,52 \\
\hline \multicolumn{2}{|l|}{$\mathrm{N}$} & 1.035 & 105 & 186 & 58 & 58 & 426 & 1.461 \\
\hline
\end{tabular}

Fuente: Álvarez de Sotomayor (2011).

la nota global (lo que supone un 4\% menos que la puntuación media de estos), mientras que los europeos occidentales lo hacen en 0,31 puntos (un $-5 \%$ ). Los latinoamericanos y los marroquíes son, por su parte, los que presentan los peores resultados. Los latinoamericanos puntúan de media 0,41 puntos menos que los nativos (un -7\%), mientras que las calificaciones de los marroquíes son inferiores en 0,67 puntos (un $-11 \%$ ).

En apariencia — sobre todo si se atiende a los valores absolutos-, estas diferencias pueden no parecer importantes, pero sí lo son. No debe olvidarse que se trata de medias en una escala del 1 al 10. De hecho, si nos centramos en las diferencias relativas, encontramos que sus valores son similares a los de la muestra andaluza de PISA 2006 en ciencias, donde los hijos de dos padres inmigrantes puntuaban un $9,7 \%$ menos $^{17}$.

Otra forma de dar cuenta de la magnitud de estas diferencias es observar cómo estas se reflejan en términos de los números de suspensos y de sobresalientes (tabla 1). Se ve, por ejemplo, que latinoamericanos y marroquíes son también los que presentan un mayor índice de materias no aprobadas, y que, de media, superan en suspensos a los nativos en más de una asignatura. Los marroquíes son, también, los que tienen el menor registro de sobresalientes.

Un cuarto indicador de interés es el porcentaje de repetidores potenciales. Los grupos de inmigrantes distinguidos muestran porcentajes de repetidores potenciales entre 9 y 13 puntos por encima de los nativos. Es decir, de haber sido estas las notas finales, el porcentaje de alumnos alóctonos que no habría superado el curso oscilaría entre el $54 \%$ de los otros APMED y el $58 \%$ de marroquíes y latinoamericanos, mientras que el de los españoles se quedaría en un $45 \%$ (tabla 1$)$.

17. Esta diferencia es de 46 puntos en términos absolutos (los nativos tienen una media de 475 y los inmigrantes, de 429), brecha que puede parecer mucho mayor que las apuntadas para el caso marbellí, pero que es similar en términos relativos a las de latinoamericanos y marroquíes. Ver datos de PISA en Carabaña (2008: 37-39). 
Tabla 2. Resultados académicos según los principales orígenes geográficos

\begin{tabular}{|c|c|c|c|c|c|c|c|c|c|c|c|c|c|c|}
\hline & & 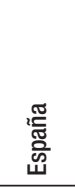 & 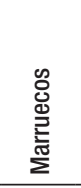 & 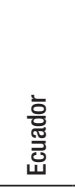 & 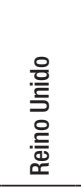 & 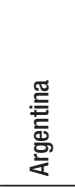 & 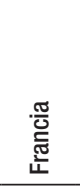 & $\begin{array}{l}\frac{\pi}{0} \\
\text { 흥 } \\
\text { 잉 }\end{array}$ & 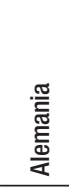 & 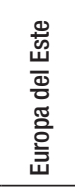 & 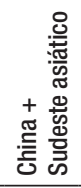 & 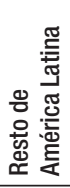 & 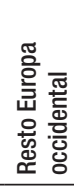 & 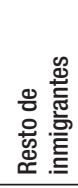 \\
\hline \multirow[t]{2}{*}{ Matemáticas } & Media & 5,09 & 4,26 & 4,31 & 4,94 & 4,88 & 4,29 & 3,86 & 4,67 & 4,83 & 4,93 & 4,15 & 4,85 & 5,00 \\
\hline & Desv. típ. & 2,23 & 2,14 & 2,38 & 2,25 & 2,35 & 2,36 & 2,08 & 2,42 & 1,97 & 1,82 & 2,20 & 1,91 & 2,33 \\
\hline \multirow[t]{2}{*}{ Lengua } & Media & 5,60 & 4,44 & 4,56 & 4,76 & 5,37 & 5,00 & 5,00 & 5,22 & 5,29 & 4,86 & 4,90 & 5,12 & 5,39 \\
\hline & Desv. típ. & 2,08 & 2,06 & 2,48 & 2,05 & 2,07 & 2,37 & 1,66 & 2,26 & 1,83 & 2,28 & 2,36 & 1,95 & 2,16 \\
\hline \multirow{2}{*}{$\begin{array}{l}\text { N. }{ }^{\circ} \\
\text { suspensos }\end{array}$} & Media & 2,73 & 4,05 & 4,24 & 3,06 & 3,39 & 4,00 & 3,52 & 3,14 & 3,25 & 3,13 & 3,72 & 3,12 & 2,68 \\
\hline & Desv. típ. & 2,69 & 3,09 & 3,01 & 3,21 & 3,18 & 2,89 & 2,57 & 2,55 & 2,63 & 2,72 & 3,12 & 2,55 & 1,99 \\
\hline \multirow{2}{*}{$\begin{array}{l}N{ }^{0} \\
\text { sobresalientes }\end{array}$} & Media & 1,38 & 0,87 & 1,18 & 1,35 & 1,15 & 1,00 & 0,91 & 1,14 & 1,08 & 1,33 & 1,12 & 1,00 & 1,64 \\
\hline & Desv. típ. & 2,04 & 1,56 & 2,05 & 1,54 & 1,49 & 2,16 & 1,04 & 1,88 & 1,25 & 2,29 & 1,69 & 1,23 & 1,81 \\
\hline \multirow[t]{2}{*}{ Nota global } & Media & 6,06 & 5,39 & 5,43 & 5,92 & 5,85 & 5,51 & 5,48 & 5,83 & 5,70 & 5,88 & 5,66 & 5,84 & 6,13 \\
\hline & Desv. típ. & 1,50 & 1,44 & 1,53 & 1,58 & 1,50 & 1,47 & 1,25 & 1,37 & 1,45 & 1,60 & 1,50 & 1,41 & 1,28 \\
\hline \multicolumn{2}{|l|}{ Repetidores (\%) } & 16,0 & 14,3 & 10,9 & 31,6 & 19,0 & 19,4 & 29,6 & 10,7 & 26,7 & 37,5 & 27,5 & 26,9 & 13,3 \\
\hline \multicolumn{2}{|c|}{ Repetidores potenciales (\%) } & 45,3 & 58,2 & 60,0 & 52,9 & 58,5 & 64,5 & 60,9 & 53,6 & 58,3 & 46,7 & 55,0 & 50,0 & 50,0 \\
\hline \multicolumn{2}{|c|}{ Tasa de idoneidad } & 71,14 & 60,34 & 60,42 & 63,16 & 64,29 & 58,06 & 44,44 & 71,43 & 54,84 & 68,75 & 63,77 & 59,26 & 80,00 \\
\hline
\end{tabular}

Finalmente, en relación con la tasa de idoneidad, ninguno de estos grupos (y únicamente los alemanes, si consideramos categorías nacionales) presenta una cifra inferior a la de los españoles. Si, como ocurría en el momento en el que se desarrolló esta investigación, la incorporación de los inmigrantes recién llegados a los distintos cursos se realizaba atendiendo a su edad, estas diferencias en las tasas de idoneidad suponen entonces que todos los grupos de origen alóctono presentarán un mayor índice de repeticiones dentro del sistema educativo que los nativos. Las diferencias son de unos 10 puntos porcentuales con respecto a los españoles.

\subsection{El efecto del origen social: ¿capital económico o capital cultural?}

A continuación, el contraste de las dos hipótesis presentadas en el marco teórico requiere del uso de técnicas de análisis multivariable. Concretamente, se han realizado regresiones múltiples mediante el método de mínimos cuadrados ordinarios. Como variable dependiente se toma la nota global por motivos ya explicados en el apartado metodológico. El procedimiento es el habitual en este tipo de estudios: primero, medir el efecto diferencial que tiene cada uno de los grupos de origen sobre la variable dependiente en cuestión, y, segundo, ver en qué medida ese diferencial cambia tras incorporar las distintas variables utilizadas como indicadores de las dos aproximaciones teóricas analizadas. La tabla 3 recoge los resultados de estos análisis, y la explicación de los mismos se detalla a continuación. 
La primera columna de coeficientes (M0) presenta las desventajas brutas, es decir, las diferencias de medias en las calificaciones sin más. La correspondiente al primer modelo (M1) incorpora la edad, el sexo y el curso como variables de control. Por un lado, se observa la incidencia positiva de los hechos de ser chica y de estar en cuarto curso, así como el efecto negativo de la edad. Por otro, se aprecia cómo, tras este primer control estadístico, todos los grupos de inmigrantes siguen puntuando por debajo de los estudiantes de origen autóctono, aunque sus desventajas disminuyen: un $12 \%$ para los latinoamericanos, un $20 \%$ para los marroquíes, un $2 \%$ para los europeos occidentales y un $41 \%$ para los otros $A P M E D$, que son, recuérdese, aquellos que partían de una posición menos desigual.

El segundo y el tercer modelos (M2 y M3) abordan el contraste de la hipótesis de la constricción económica, la primera de las explicaciones expuestas. Como principal variable aproximativa, se utiliza el ISEI. Este índice es el resultado de una suma ponderada de la educación y los ingresos medios de las personas que ocupan cada categoría ocupacional controlando los efectos de la edad ${ }^{18}$. Eso hace que esté fuertemente relacionado con el nivel educativo y - lo que más importa en este punto- con los ingresos (Ganzeboom et al., 1992). Por lo tanto, lo que en cierto modo se hace aquí al tomarlo como representante del nivel económico es recorrer el camino inverso al que fue parcialmente tomado para la creación del mismo. Esta aproximación será, a priori, más ajustada una vez que el nivel educativo de los padres sea tenido en cuenta en los análisis multivariables, ya que, entonces, lo que el ISEI estaría captando en mayor medida serían los ingresos estables de las ocupaciones ${ }^{19}$. Es por eso por lo que el nivel educativo de los padres se incorpora a posteriori (M3). Esta segunda variable capta, además, por sí misma, el capital humano parental, factor de suma importancia según lo demostrado desde hace décadas por la sociología y la economía de la educación.

$\mathrm{Al}$ añadir el ISEI a la regresión se comprueba que su efecto sobre la variable dependiente es positivo, aunque no muy fuerte ${ }^{20}$. Por sí solo explica porcentajes muy modestos de la varianza. Asimismo, la inclusión del ISEI afecta de manera muy distinta a las desventajas de los cuatro grandes grupos de origen diferenciados. Ello es debido a los diferentes perfiles que estos presentan respecto a dicho índice (tabla 4). Para los latinoamericanos y para los marroquíes, que, sorprendentemente, presentan una media en el ISEI similar e incluso ligeramente superior a la de los nativos, la incorporación de este indicador apenas conlleva variaciones significativas en las desventajas restantes del modelo anterior. Por su parte, las implicaciones sobre las desventajas de los europeos occidentales y del grupo otros APMED sí que son apreciables, pero antagónicas entre sí. En el caso del resto de los APMED, que, a tenor de los descriptivos, son los que se

18. La corrección por la edad es necesaria, debido a que esta variable influye en las otras dos (educación e ingresos).

19. La aplicación de esta misma lógica puede verse en Martínez García (2002: 107).

20. Esto se aprecia mejor a través de los coeficientes estandarizados (tabla A.1, en el anexo), al no estar estos afectados por la unidad de medición de la variable, que, en este caso, comporta un intervalo muy amplio (ISEI toma valores que van desde 16 hasta 85 en la población analizada). 
Tabla 3. Regresiones múltiples (MCO). Resultados educativos, nivel económico y nivel sociocultural

\begin{tabular}{|c|c|c|c|c|c|c|}
\hline & Variables & $\begin{array}{l}\text { M0 } \\
\text { (B) }\end{array}$ & $\begin{array}{l}\text { M1 } \\
\text { (B) }\end{array}$ & $\begin{array}{l}\text { M2 } \\
\text { (B) }\end{array}$ & $\begin{array}{l}\text { M3 } \\
\text { (B) }\end{array}$ & $\begin{array}{l}\text { M4 } \\
\text { (B) }\end{array}$ \\
\hline & \multicolumn{6}{|l|}{ Origen (Ref.: españoles de origen nativo) } \\
\hline & Europa occidental & $-0,308$ & $-0,301$ & $-0,396$ & $-0,473$ & $-0,490$ \\
\hline & América Latina & $-0,414$ & $-0,364$ & $-0,334$ & $-0,405$ & $-0,163$ \\
\hline & Marruecos & $-0,674$ & $-0,542$ & $-0,529$ & $-0,550$ & $-0,219$ \\
\hline & Otros APMED & $-0,218$ & $-0,129$ & 0,001 & $-0,132$ & $-0,070$ \\
\hline & Resto de inmigrantes & 0,030 & 0,085 & $-0,036$ & $-0,095$ & $-0,047$ \\
\hline & Sexo: mujeres (Ref.: hombres) & & 0,395 & 0,408 & 0,421 & 0,335 \\
\hline & Edad & & $-0,462$ & $-0,441$ & $-0,428$ & $-0,381$ \\
\hline & Curso: cuarto de ESO (Ref.: tercero de ESO) & & 0,736 & 0,693 & 0,689 & 0,647 \\
\hline \multirow{4}{*}{ 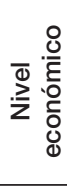 } & Estatus socioeconómico (ISEI) & & & 0,014 & 0,010 & 0,006 \\
\hline & $\begin{array}{l}\text { Nivel educativo de los padres } \\
\text { (Ref.: sin estudios / con estudios primarios) }\end{array}$ & & & & & \\
\hline & Estudios secundarios & & & & 0,200 & 0,051 \\
\hline & Estudios universitarios & & & & 0,391 & 0,146 \\
\hline \multirow{19}{*}{ 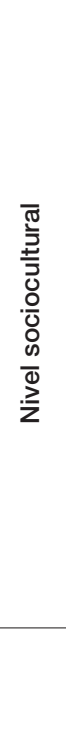 } & Recursos educativos en el hogar & & & & & \\
\hline & Sitio tranquilo & & & & & 0,247 \\
\hline & Ordenador & & & & & 0,291 \\
\hline & Diccionario & & & & & 0,302 \\
\hline & Calculadora & & & & & 0,362 \\
\hline & Más de 50 libros & & & & & 0,250 \\
\hline & Clases culturales extraescolares & & & & & \\
\hline & Música & & & & & 0,472 \\
\hline & Idiomas & & & & & 0,363 \\
\hline & Arte & & & & & 0,282 \\
\hline & Actividades culturales & & & & & \\
\hline & Ir al teatro & & & & & 0,035 \\
\hline & Tocar un instrumento musical & & & & & 0,043 \\
\hline & Ir a museos & & & & & 0,168 \\
\hline & Leer libros no relacionados con el IES & & & & & 0,014 \\
\hline & Afición por la lectura & & & & & 0,377 \\
\hline & Constante & & 12,566 & 11,689 & 11,449 & 9,084 \\
\hline & $\mathrm{N}$ & & 1.375 & 1.326 & 1.326 & 1.291 \\
\hline & $\mathrm{R}^{2}$ & & 0,112 & 0,127 & 0,133 & 0,247 \\
\hline
\end{tabular}

Fuente: Álvarez de Sotomayor (2011).

encuentran en una posición menos favorable respecto a este indicador, cuando se tiene en cuenta el estatus ocupacional de los padres su desventaja frente a los nativos se desvanece por completo. Con los hijos de europeos occidentales se da el efecto contrario: al mantener constante esta variable su desventaja respecto a los autóctonos crece (en torno a un 28\%) como consecuencia de ser el grupo cuyas familias disfrutan de una mejor condición socioeconómica. 
Tabla 4. Estatus socioeconómico y nivel educativo de padres de nativos y de inmigrantes

\begin{tabular}{|c|c|c|c|c|}
\hline \multirow[b]{2}{*}{ Origen del alumnado } & \multirow{2}{*}{$\begin{array}{c}\text { Estatus } \\
\text { socioeconómico }\end{array}$} & \multicolumn{3}{|c|}{ Nivel educativo de los padres } \\
\hline & & $\begin{array}{l}\text { Sin estudios } \\
\text { o con estudios } \\
\text { primarios } \\
(\%)\end{array}$ & $\begin{array}{c}\text { Estudios } \\
\text { secundarios y } \\
\text { de grado medio } \\
(\%) \\
\end{array}$ & $\begin{array}{c}\text { Estudios } \\
\text { universitarios } \\
(\%) \\
\end{array}$ \\
\hline Nativos & 40,8 & 24,6 & 57,2 & 18,2 \\
\hline Europa occidental & 48,4 & 4,8 & 41,7 & 53,4 \\
\hline América Latina & 42,1 & 10,4 & 44,5 & 45,0 \\
\hline Marruecos & 45,5 & 22,6 & 49,1 & 28,3 \\
\hline Otros APMED & 38,9 & 1,8 & 37,0 & 61,1 \\
\hline Resto de inmigrantes & 52,2 & 5,56 & 38,89 & 55,6 \\
\hline Total de inmigrantes & 44,2 & 9,3 & 43,2 & 47,6 \\
\hline Total de alumnos & 41,8 & 20,2 & 53,1 & 26,7 \\
\hline
\end{tabular}

Fuente: Álvarez de Sotomayor (2011).

Por lo tanto, de acuerdo con los datos, la desventaja del grupo otros $A P M E D$ sería la única que estaría explicada de forma importante por las diferencias económicas, mientras que en la situación opuesta se encontrarían los originarios de países de Europa occidental, para los que su mejor posición relativa en la escalera social supondría un apoyo que les hace no estar aún más por debajo de los resultados de los nativos. Sin embargo, los datos mostrados hacen que nos cuestionemos si el ISEI estará captando plenamente las diferencias económicas existentes entre unas y otras familias. Principalmente, porque la fotografía que ofrece (inmigrantes procedentes de países menos desarrollados con un nivel parejo e incluso ligeramente superior al de los nativos) difiere sustancialmente de la que tantos otros estudios han probado en este país (Bernardi et al., 2011) y en la comunidad autónoma andaluza (Rinken et al., 2010).

Al tener en cuenta también los estudios de los padres (M3) - lo que, como se ha explicado, en un principio supondría que el ISEI captase en mayor medida la parte del estatus ocupacional relacionada con los ingresos y que, por ende, funcionase mejor como representante del nivel económico-, el efecto de este índice sobre las tres variables dependientes disminuye parcialmente sin que su signo varíe (tabla 3). Tampoco cambia, pues, el modo en que afecta a las desigualdades entre inmigrantes y nativos. Por otro lado, de la incorporación de esta otra variable es reseñable, primero, que el nivel educativo de los padres ejerce un efecto positivo y fuerte sobre las calificaciones de los estudiantes y, segundo, que las desventajas académicas de los inmigrantes se incrementan aún más una vez es considerada. Y ello es debido a que los padres de estos chicos superan en todos los casos claramente (para los cuatro grandes grupos de origen inmigrante) a los de los nativos en este aspecto (tabla 4). La interpretación es clara: el nivel de estudios de los padres 
no solo no es un factor que esté detrás de la desventaja relativa de estos alumnos, sino que más bien ocurre lo contrario: constituye para ellos un recurso que les ayuda a que esta no sea todavía mayor. Será este un elemento a tener muy en cuenta en futuras investigaciones sobre el caso español, ya que, según datos de PISA y de la EPA, se trata de un rasgo generalizado en Andalucía y en la media del conjunto del país (Álvarez-Sotomayor et al., 2015: 142; Rinken et al., 2011; Schnell y Azzolini, 2015).

Por su parte, para el contraste de la explicación del nivel sociocultural del hogar (hipótesis 2) se efectúa el cuarto modelo de regresión (M4 de la tabla 3), que incorpora las variables correspondientes a los tres indicadores socioculturales considerados. Esta hipótesis se verá confirmada en la medida en que tales variables tengan un efecto independiente sobre los resultados educativos analizados después de haber controlado estadísticamente el nivel económico de la familia.

Los coeficientes muestran que el efecto de dichas variables sobre el rendimiento académico es positivo en todos los casos y fuerte en muchos de ellos. En su conjunto, su incorporación explica una parte importante de la varianza total de los resultados analizados. Además, al introducirlas en los análisis el efecto de las variables del nivel económico se ve reducido.

En lo que se refiere a la incidencia sobre el diferencial académico de los inmigrantes, en la tabla 3 se observa que mientras las brechas que separan a latinoamericanos y a marroquíes del rendimiento de los nativos se reducen de forma muy importante tras introducir estas variables en las regresiones, las que afectan a los europeos occidentales y al grupo otros $A P M E D$ o se contraen muy levemente o incluso se amplían. No obstante, al introducir paso a paso cada uno de los tres indicadores del nivel sociocultural (tablas 6 y 7), se comprueba que su efecto sobre estas diferencias es desigual.

Por un lado, las clases extraescolares y los recursos educativos provocan el descenso de las desventajas para todos los grupos inmigrantes (tabla 5), aunque este es mucho menor en el caso de los europeos occidentales, debido a que ellos son los únicos que no se encuentran en una clara situación de menor disponibilidad de tales recursos, tal y como se aprecia en la tabla 7.

Por otro lado, exceptuando a los marroquíes, la inclusión en el modelo de las actividades culturales (tabla 6) conlleva el efecto contrario: la desventaja académica de los inmigrantes tiende a hacerse todavía más amplia, sobre todo para los europeos occidentales y, en menor medida, para los otros APMED, que son los grupos que, como puede verse en la tabla 8, presentan los mayores niveles a este respecto.

Por consiguiente, aunque los tres indicadores socioculturales afectan positivamente al rendimiento del conjunto de los alumnos, no ayudan a explicar las desventajas analizadas en el mismo sentido: mientras que los dos primeros (recursos culturales y actividades extraescolares) explican una parte importante del diferencial negativo que presentan los hijos de inmigrantes, el tercero (actividades culturales) contribuye a que este no sea incluso más amplio para todos los grupos salvo para los marroquíes. Y ello debido a la desigual situación relativa 
Tabla 5. Regresiones múltiples (MCO). Resultados académicos, nivel económico y nivel sociocultural (con recursos educativos en el hogar y clases extraescolares)

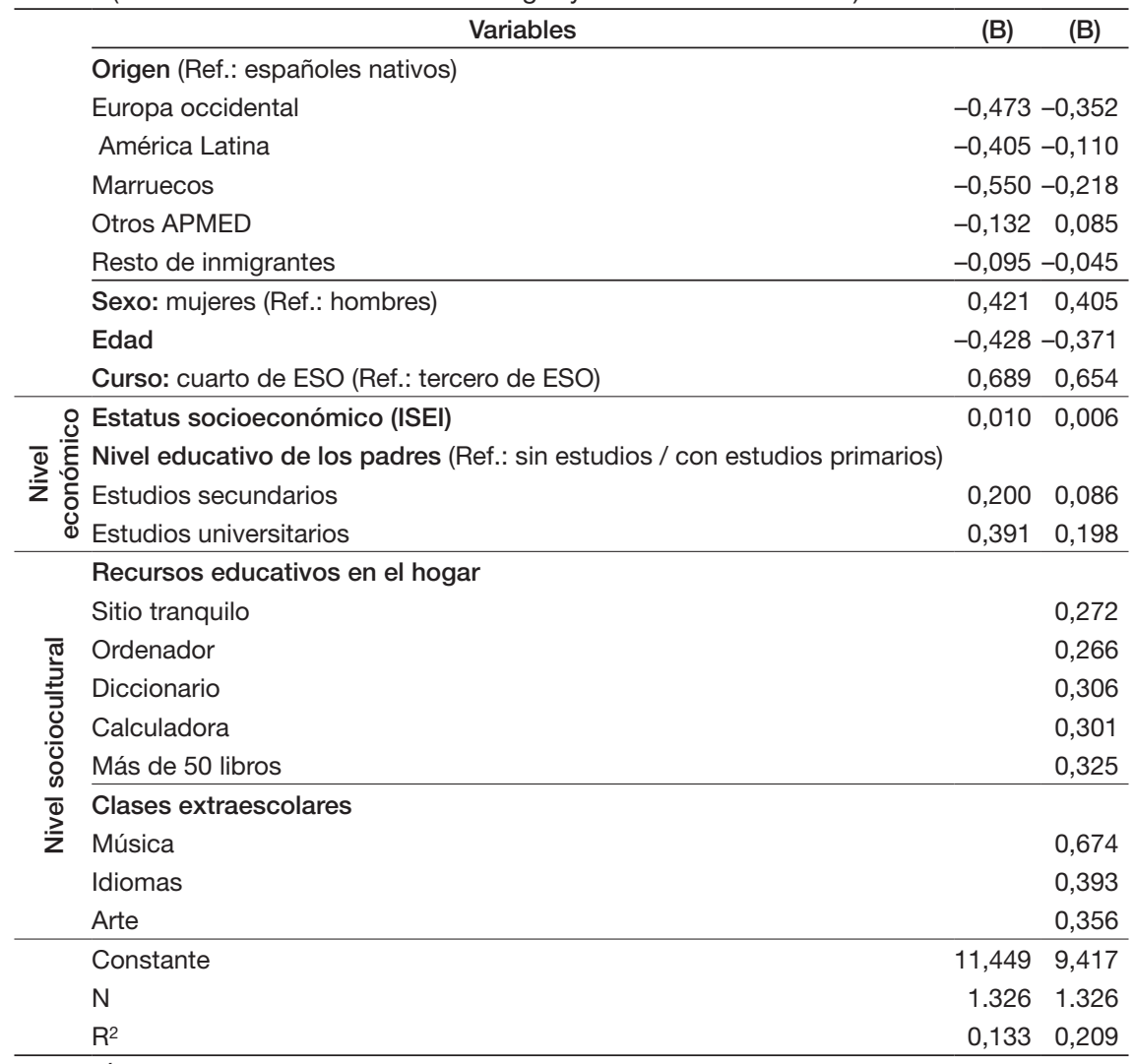

Fuente: Álvarez de Sotomayor (2011).

de este alumnado frente a los tres indicadores (tablas 7 y 8 ) y a los diferentes efectos de composición resultantes.

En suma, el origen social de los alumnos explica una parte importante de las diferencias académicas halladas entre los nativos y los distintos grupos de inmigrantes. Concretamente, si se tienen en cuenta todas las variables que se han descubierto relevantes a la hora de predecir las calificaciones - las recogidas en la tabla 3-, comprobamos que las desventajas brutas de los marroquíes, del grupo otros APMED y de los latinoamericanos se reducen fuertemente (un $68 \%$ para los dos primeros y un $61 \%$ para el último). Por el contrario, en el caso de los europeos occidentales, a igualdad de origen social su desventaja con respecto a los nativos varía en una proporción similar pero en sentido contrario (crece un 60\%), lo que da cuenta de la posición social ventajosa de sus familias (gráfico 1). Ello obliga, al mismo tiempo, a buscar el porqué de sus peores resultados en otro tipo de condicionantes. 
Tabla 6. Regresiones múltiples (MCO). Resultados académicos, nivel económico y nivel sociocultural (con actividades culturales)

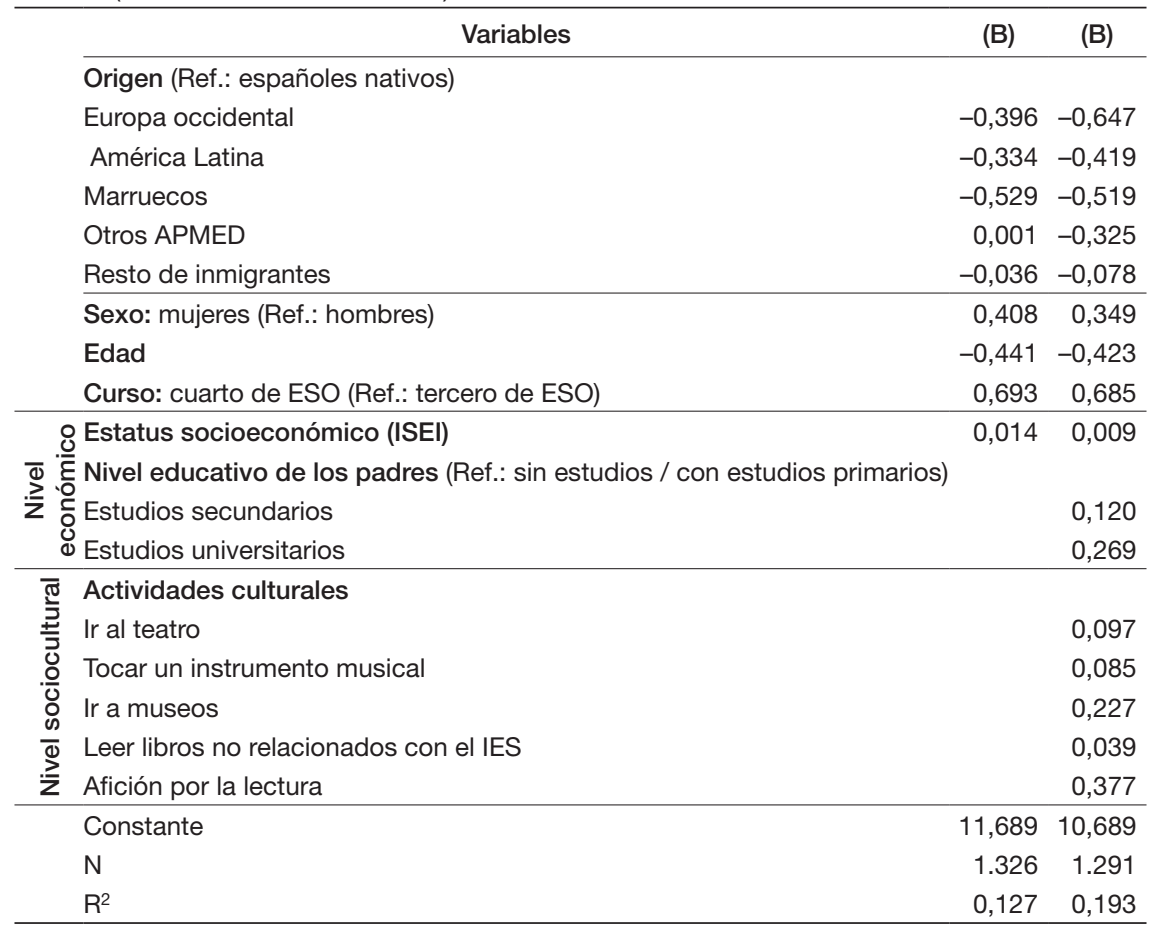

Fuente: Álvarez de Sotomayor (2011).

Tabla 7. Recursos educativos y asistencia a clases extraescolares de contenido cultural según grupos de origen (en \%)

\begin{tabular}{lrcrrrrr}
\hline & & $\begin{array}{c}\text { Europa } \\
\text { occidental }\end{array}$ & $\begin{array}{c}\text { América } \\
\text { Latina }\end{array}$ & Marruecos & $\begin{array}{c}\text { Otros } \\
\text { APMED }\end{array}$ & $\begin{array}{c}\text { Resto de } \\
\text { inmigrantes }\end{array}$ & Total \\
\hline Sitio tranquilo para estudiar & 77,9 & 73,3 & 68,3 & 63,8 & 69,0 & 89,5 & 75,6 \\
Ordenador & 93,6 & 94,3 & 80,6 & 70,7 & 81,0 & 84,2 & 90,4 \\
Diccionario & 95,3 & 95,2 & 83,3 & 69,0 & 75,9 & 89,5 & 91,9 \\
Calculadora & 93,7 & 95,2 & 89,8 & 70,7 & 81,0 & 94,7 & 91,9 \\
Más de 50 libros & 58,5 & 57,1 & 33,9 & 32,8 & 48,3 & 57,9 & 53,8 \\
Clases de música & 6,1 & 8,6 & 6,5 & 5,2 & 6,9 & 5,3 & 6,3 \\
Clases de arte & 8,9 & 10,5 & 3,2 & 12,1 & 13,8 & 15,8 & 8,7 \\
Clases de idiomas & 39,1 & 20,0 & 20,4 & 25,9 & 24,1 & 21,1 & 34,0 \\
\hline
\end{tabular}

Fuente: Álvarez de Sotomayor (2011). 
Tabla 8. Actividades culturales según grupos de origen (medias). Desviaciones típicas entre paréntesis

\begin{tabular}{lrrrrrrr}
\hline & Nativos & $\begin{array}{c}\text { Europa } \\
\text { occidental }\end{array}$ & $\begin{array}{c}\text { América } \\
\text { Latina }\end{array}$ & Marruecos & $\begin{array}{c}\text { Otros } \\
\text { APMED }\end{array}$ & $\begin{array}{c}\text { Resto de } \\
\text { inmigrantes }\end{array}$ & Total \\
\hline Ir al cine & 2,90 & 3,10 & 2,97 & 2,95 & 2,58 & 3,11 & 2,92 \\
& $(1,01)$ & $(1,14)$ & $(1,15)$ & $(1,13)$ & $(1,13)$ & $(1,05)$ & $(1,05)$ \\
Tocar un instrumento & 1,92 & 2,28 & 2,04 & 1,91 & 2,12 & 1,58 & 1,96 \\
& $(1,48)$ & $(1,61)$ & $(1,51)$ & $(1,38)$ & $(1,55)$ & $(1,02)$ & $(1,49)$ \\
Ir a museos 0 exposiciones & 1,35 & 1,62 & 1,47 & 1,34 & 1,63 & 1,42 & 1,40 \\
& $(0,59)$ & $(0,80)$ & $(0,74)$ & $(0,55)$ & $(0,77)$ & $(0,61)$ & $(0,64)$ \\
Leer libros no relacionados & 2,17 & 2,83 & 2,26 & 2,36 & 2,77 & 2,37 & 2,26 \\
con el IES & $(1,36)$ & $(1,48)$ & $(1,39)$ & $(1,43)$ & $(1,60)$ & $(1,67)$ & $(1,40)$ \\
Aficionados a la lectura & $57,70 \%$ & $68,27 \%$ & $61,67 \%$ & $64,81 \%$ & $70,69 \%$ & $52,63 \%$ & $59,68 \%$ \\
\hline
\end{tabular}

Fuente: Álvarez de Sotomayor (2011).

Por consiguiente, en hipotéticas condiciones de equidad en el origen social en cuanto a las variables consideradas, los españoles seguirían siendo los que obtendrían mejores resultados, pero lo harían seguidos a menos distancia por los distintos grupos de APMED. En concreto, el grupo de otros APMED continuaría ocupando la segunda posición, los latinoamericanos pasarían a la tercera y los marroquíes, a la cuarta. Por el contrario, los europeos occidentales - que suponen la inmensa mayoría de los alumnos procedentes de países altamente desarrollados en el caso estudiado- verían aumentada su desventaja respecto a los nativos, y pasarían de la tercera a la quinta y última posición.

Igualmente, los resultados ratifican - al menos parcialmente- las dos hipótesis planteadas. Muestran que tanto el capital económico como el cul-

Gráfico 1. Desventajas de los inmigrantes en la nota global según los modelos de origen social presentados y según grupos de origen

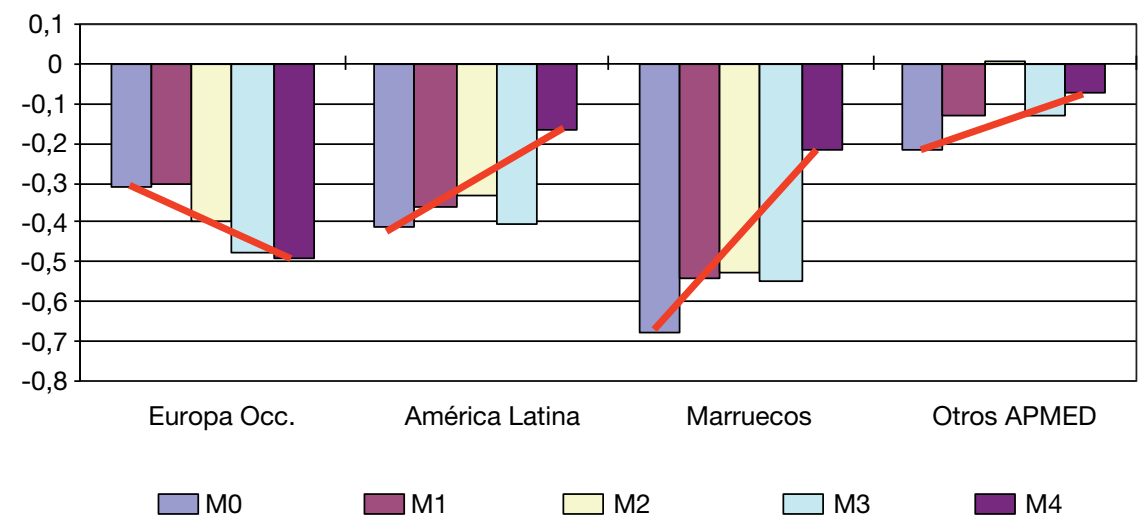

Fuente: Álvarez de Sotomayor (2011). 
tural median como factores entre el origen social y los resultados educativos desiguales entre hijos de inmigrantes e hijos de nativos. No obstante, de las dos tesis contrastadas, es la de la desigualdad respecto al capital cultural la que tiene un mayor poder explicativo sobre tales desigualdades. Los efectos de composición en referencia a esta forma de capital de los distintos grupos de APMED explican en mucho mayor grado sus desventajas académicas en relación con los estudiantes nativos.

\section{Conclusiones}

Este trabajo se planteaba como objetivo principal analizar el efecto del origen social sobre el rendimiento educativo diferencial del alumnado inmigrante. Por un lado, se quería conocer el sentido y el grado de dicho efecto, lo cual le empareja con aquellos estudios que tienen como primera inquietud analítica discernir en qué medida estas desigualdades se deben a la dispar posición de la población inmigrante en la estructura social de la sociedad de destino. Por otro lado, el trabajo se planteaba desentramar el efecto del origen social a partir del contraste de las dos tesis de mayor relevancia en la literatura sociológica: la de la desigualdad económica y la de la desigualdad sociocultural. Todo ello salvando la principal carencia que presenta la gran mayoría de antecedentes empíricos centrados en el contexto español: la no distinción del alumnado inmigrante en función de orígenes nacionales o geográficos.

Para alcanzar el objetivo mencionado, un primer paso necesario era describir los resultados de los distintos grupos de inmigrantes diferenciados y ponerlos en relación respecto a los de los nativos. En este sentido los datos constatan que, al igual que se ha encontrado en la inmensa mayoría de estudios desarrollados en este país y en otros contextos nacionales, los alumnos de origen inmigrante obtienen, por término medio, peores calificaciones que los nativos. Concretamente, se ha hallado que los asiáticos (de China y de diversos países del sudeste asiático), los europeos occidentales y los europeos del Este (fundamentalmente, ucranianos) son, por ese orden, los que menos se distancian de las notas de los nativos en Marbella, mientras que los latinoamericanos y, en mayor medida, los marroquíes son los que más se alejan de ellas. Estos resultados por grupos de origen están en la línea de lo hallado por Cebolla-Boado y Garrido (2008) en una muestra española de educación primaria y se corresponden, igualmente, con las tendencias más amplias halladas en Europa, donde los estudiantes con origen en países no europeos menos desarrollados muestran un peor rendimiento que los nativos, y las minorías de procedencia europea también lo muestran pero a una distancia menor (Heath et al., 2008: 216).

A partir de ahí, del análisis del efecto del origen social puede concluirse lo siguiente: en primer lugar, y en línea con la literatura especializada, el origen social se ha confirmado como un factor de peso a la hora de explicar las desigualdades educativas que afectan a los hijos de inmigrantes. Así, cuando este es tenido en cuenta, se desvanece una parte importante de las desventajas 
académicas de los grupos con origen en países menos desarrollados. Con los europeos occidentales ocurre lo contrario, con lo que se revela que su mejor posición relativa respecto a los grupos anteriores descansa en gran medida en su mayor estatus socioeconómico.

A falta de analizar el impacto de otra clase de condicionantes, este importante peso explicativo del origen social sobre la desventaja académica de los APMED significaría que, en buen grado, la raíz de tal desigualdad se encuentra en factores que no son completamente específicos de los inmigrantes, sino que afectan al conjunto de la población estudiante. La implicación política que se deriva de ello es clara e importante: las medidas educativas necesarias para mejorar el rendimiento académico de todos estos jóvenes de origen inmigrante serían, en gran medida, las mismas que las que resulten efectivas para hacer lo propio con los nativos; medidas que logren que el sistema educativo sea más eficaz a la hora de corregir esa porción de brecha académica que es consecuencia del origen socioeconómico de los alumnos. Por su parte, la explicación al porqué de la desventaja académica de los hijos de inmigrantes procedentes de Europa occidental tendrá que buscarse en otros factores que no han tenido cabida en este trabajo.

En segundo lugar, en cuanto al análisis de los dos mecanismos explorados, la evidencia hallada es mixta, pues se comprueba que tanto el nivel económico como el capital cultural afectan al rendimiento académico diferencial de los hijos de inmigrantes. Sin embargo, el efecto de las variables socioculturales es mayor. Es decir, más que el capital económico (hipótesis 1) sería el capital cultural (hipótesis 2) el que explicaría la mediación entre el origen social y tales desigualdades. Y ello como consecuencia de las importantes diferencias composicionales que hay respecto a esta forma de capital entre el alumnado nativo y los distintos grupos de origen inmigrante. No obstante, no hay que dejar de tener en cuenta los matices señalados a este respecto a lo largo del artículo.

Bajo un prisma bourdiano, esta relevancia explicativa de las diferencias en torno al capital cultural pondría de manifiesto que, como ocurre con el resto de estudiantes, el origen social del alumnado inmigrante no solo le condiciona académicamente por la vía de los recursos económicos, sino también por la vía de los estilos, los hábitos, los recursos y las disposiciones culturales que les son transmitidos en su familia.

\section{Referencias bibliográficas}

Álvarez de Sotomayor, Alberto (2011). El rendimiento académico de los alumnos inmigrantes en España: Un estudio de caso [en línea]. Granada: Universidad de Granada. Tesis doctoral. <http://digibug.ugr.es/bitstream/10481/20187/1/20152784. pdf> [Consulta: noviembre 2014].

Álvarez-Sotomayor, Alberto; Martínez-Cousinou, Gloria y Gutiérrez-Rubio, David (2015). «Cuando la segunda generación no se queda atrás: Evidencias sobre el rendimiento académico de los hijos de inmigrantes en el caso andaluz». Estudios sobre Educación [en línea], 28, 51-78. $<$ http://dx.doi.org/10.15581/004.28.51-78>. 
Aparicio, Rosa y Tornos, Andrés (2006). Hijos de inmigrantes que se hacen adultos: marroquies, dominicanos, peruanos. Madrid: Ministerio de Trabajo y Asuntos Sociales.

Bernardi, Fabrizio; Garrido, Luis y Miyar, María (2011). «The recent fast upsurge of immigrants in Spain and their employment patterns and occupational attainment». International Migration [en línea], 49 (1), 148-187. <http://dx.doi.org/10.1111/j.1468-2435.2010.00610.x>.

Boudon, Raymond (1974). Education, Opportunity and Social Inequality. Nueva York: Wiley-Interscience.

Bourdieu, Pierre (1980). El sentido práctico. Madrid: Siglo XXI, 2007.

- (1986). "The forms of capital». En: Halsey, Albert H.; Lauder, Hugh; Brown, Phillip y Stuart Wells, Amy (eds.). Education: Culture, economy and society. Oxford: Oxford University Press, 1997.

Bourdieu, Pierre y Passeron, Jean C. (2008). La reproducción: Elementos para una teoría del sistema de enseñanza. Madrid: Popular.

Breen, Richard y Golthorpe, John H. (1997). «Explaining educational differentials: Towards a formal rational action theory». Rationality and Society [en línea], 9 (3), 275-305. <http://dx.doi.org/10.1177/104346397009003002>.

BreEN, Richard y Jonsson, Jan O. (2005). «Inequality of Opportunity in comparative perspective». Annual Review of Sociology [en línea], 31, 223-43. <http://dx.doi.org/10.1146/annurev.soc.31.041304.122232>.

Calero, Jorge; Choi, Álvaro y Waisgrais, Sebastián (2009). "Determinantes del rendimiento educativo del alumnado de origen nacional e inmigrante en PISA2006». Cuadernos Económicos de ICE, 78, 281-310.

Carabaña, Julio (1999). Dos estudios sobre movilidad ocupacional. Madrid: Fundación Argentaria.

(2008). Las diferencias entre regiones y paises en las pruebas PISA. Documento del Colegio Libre de Eméritos, 2.

Cassady, Jerrell C. (2001). "Self reported GPA and SAT: A methodological note». Practical Assesment, Research \& Evaluation, 7 (12), 1-6.

Cebolla-Boado, Héctor (2008). A non Ethnic Explanation of Immigrants Educational Disadvantage: The Case of Lower Secondary Education in France. Madrid: Instituto Juan March de Estudios e Investigaciones. Tesis doctoral dirigida por Anthony Heath.

Cebolla-Boado, Héctor y Garrido, Luis (2008). «Sobre la desventaja educativa de los inmigrantes». Indice: Revista de Estadística y Sociedad, 30, 21-23.

Consejería de Educación de la Junta de Andalucía (2007). Estadística de alumnado escolarizado en los centros docentes de Andalucía. En: <http://www. juntadeandalucia.es/educacion/webportal/web/estadisticas/alumnado-escolarizadoen-el-sistema-educativo-andaluz> [Consulta: 20 enero 2014].

Crook, Christopher J. (1997). Cultural Practices and Socioeconomic Attainment: The Australian Experience. Westport Conn: Greenwood Press.

Defensor del Pueblo (2003). Escolarización del alumnado de origen inmigrante en España: Análisis descriptivo y estudio empirico [en línea]. Madrid: Defensor del Pueblo. Informes monográficos. <http://www.defensordelpueblo.es/es/Documentacion/Publicaciones/monografico/contenido_1261584551261.html> [Consulta: 17 enero 2014].

De Graff, Nan Dirk; De Graff, Paul M. y Kraaykamp, Gerbert (2000). «Parental Cultural Capital and Educational Attainment in the Netherlands: A Refinement of 
the Cultural Capital Perspective». Sociology of Education [en línea], 73 (2), 92-111. <http://dx.doi.org/10.2307/2673239>.

Erikson, Robert y Jonsson, Jan O. (1996). «Introduction: Explaning Class Inequality in Education: The Swedish Test Case». En: Erikson, Robert y Jonsson, Jan O. (eds.). Can Education be Equalized?: The Swedish in Comparative Perspective. Oxford: Westview Press.

Frucot, Veronique G., y Cook, Gail L. (1994). «Further research on the accuracy of students' self-reported grade point averages, SAT scores, and course grades». Perceptual and Motor Skills, 79 (2), 743-46. <http://dx.doi.org/10.2466/pms.1994.79.2.743>.

Fullana, Judit; Besalú, Xavier y Vilà, Montserrat (2003). Alumnes d'origen africà a l'escola. Girona: CCG Edicions.

Ganzeboom, Harry B.G.; De Graaf, Paul y Treiman, Donald J. (1992). «A Standard International Socio-Economic Index of Occupational Status». Social Science Research [en línea], 21, 1-56. <http://dx.doi.org/10.1016/0049-089X(92)90017-B>.

Goldman, Bert A., Flake, Wesley L. y Matheson, Mary B. (1990). "Accuracy of college students' perceptions of their SAT scores and high school and college grade point averages relative to their ability». Perceptual and Motor Skills, 70 (2), 514. <http://dx.doi.org/10.2466/PMS.70.2.514-514>.

Heath, Anthony y Brinbaum, Yaël (2007). «Explaining ethnic inequalities in educational attainment». Ethnicities, 7 (3), 291-305.

Heath, Anthony; Rothon, Catherine y Kilpi, Elina (2008). «The Second Generation in Western Europe: Education, Unemployment, and Occupational Attainment». Annual Review of Sociology [en línea], 34, 211-235. <http://dx.doi.org/10.1146/annurev.soc.34.040507.134728>.

JÆGer, Mads M. (2009). «Equal access but unequal outcomes: Cultural capital and educational choice in a meritocratic society». Social Forces [en línea], 87 (4), 19431971. <http://dx.doi.org/10.1353/sof.0.0192>.

Kao, Grace y Thompson, Jeniffer S. (2003). "Racial and Ethnic Stratification in Educational Achievement and Attainment». Annual Review of Sociology [en línea], 29, 417-442. <http://dx.doi.org/10.1146/annurev.soc.29.010202.100019>.

Katz, Tally; Shavit, Yossi y De Graaf, Nan Dirk (1993). Marital and Cultural Resources in Educational Attainment: Comparing Israel and The Netherlands. Comunicación presentada en el Research Comitee on Social Stratification (RC28). Trondheim: International Sociology Association.

Kingston, Paul W. (2001). "The Unfulfilled Promise of Cultural Capital Theory». Sociology of Education, número extra [en línea], 88-99. <http://dx.doi.org/10.2307/2673255>.

Kuehn Dumpiérrez, Robert (2009). «No sólo turistas y jubilados: Acerca de la (invisible) presencia de inmigrantes de Europa occidental en España». En: ReHER, David y Requena, Miguel (eds.). Las múltiples caras de la inmigración en España. Madrid: Alianza.

Kuncel, Nathan R.; Credé, Marcus y Thomas, Lisa L. (2005). «The validity of self-reported grade point averages, class ranks, and test scores: A meta-analysis and review of the literature». Review of Educational Research [en línea], 75 (1), 63-82. <http://dx.doi.org/10.3102/00346543075001063>. 
Lareau, Annete y Weininger, Elliot B. (2003). «Cultural Capital in Educational Research: A Critical Assessment». Theory and Society [en línea], 32 (5-6), 567-606. <http://dx.doi.org/10.1007/1-4020-2589-0_6>.

Levels, Mark; Dronkers, Jaap y KraAykamp, Gerbert (2008). «Immigrant children’s educational achievement in western countries: Origin, destination, and community effects on mathematical performance». American Sociological Review [en línea], 73 (5), 835-853.

<http://dx.doi.org/10.1177/000312240807300507>.

LuCAs, Samuel R. (2001). «Effectively Mainteined Inequality». American Journal of Sociology [en línea], 106, 1642-1690.

<http://dx.doi.org/10.1086/321300>.

Manzano Espinosa, Dulce (2001). Inequality and Education: The Dynamics of Inequality in Educational Opportunities in Spain (1941-1971). Madrid: CEACS de la Fundación Juan March.

Martínez García, José S. (2002). ¿Habitus o calculus?: Dos intentos de explicar la dinámica de las desigualdades educativas en España entre 1907 y 1966, con datos de la Encuesta Sociodemográfica. Madrid: Universidad Autónoma de Madrid. Tesis doctoral dirigida por Julio Carabaña.

- (2011). "Género y origen social: Diferencias grandes en fracaso escolar administrativo y bajas en rendimiento educativo». RASE: Revista de la Asociación de Sociología de la Educación, 4 (3), 270-282.

Mediavilla, Mauro y Calero, Jorge (2009). «Determinantes internos y externos en el proceso de aprendizaje: Una aproximación al caso español a partir de la ECV-05». Revista Iberoamericana de Educación, 50 (6), 1-11.

Ministerio de Empleo y Seguridad Social (2008). Anuario estadístico de inmigración 2008 [en línea]. <http://extranjeros.empleo.gob.es/es/ObservatorioPermanente Inmigracion/Anuarios> [Consulta: mayo 2016].

OECD (2011). «How Are School Systems Adapting to Increasing Numbers of Immigrant Students?». PISA in Focus [en línea], 11. OECD Publishing. <http://dx.doi.org/10.1787/5k9h362hs646-en>.

Rinken, Sebastian; Alvarez-Sotomayor, Alberto y Galera, Gema (2010), Informe anual Andalucía Inmigración 2008. Sevilla: Consejería de Empleo de la Junta de Andalucía.

Rinken, Sebastian; Álvarez-Sotomayor, Alberto; Cortés María P. y Galera, Gema (2011). «El (des)empleo inmigrante en España en tiempos de crisis económica: Un examen empírico de tres factores explicativos». Sociología del Trabajo, 72, 41-62.

Roscigno, Vincent J. y Ainswoth-Darnell, James W.R. (1999). «Race, Cultural Capital and Educational Resources: Persistent Inequalities and Achievement Returns». Sociology of Education [en línea], 72, 158-178. <http://dx.doi.org/10.2307/2673227>.

Schnell, Philipp y Azzolini, Davide (2015). "The academic achievements of immigrant youths in new destination countries: Evidence from southern Europe». Migration Studies [en línea], 3 (2), 217-240.

<http://dx.doi.org/10.1093/migration/mnu040>.

Schnepf, Sylke V. (2008). «Inequality of Learning amongst Immigrant Children in Industrialised Countries». IZA Discussion Paper Series, 3337.

Serra Salamé, Carles y Palaudàrias, Josep M. (2008). Estudi dels processos de continü̈tat $i$ discontinuïtat en el pas de l'escolarització obligatòria a la postobligatòria entre els alumnes membres de families immigrades. Barcelona: Fundació Jaume Bofill. 
Stanat, Petra y Christensen, Gayle (2006). Where immigrant students succeed: A comparative review of performance and engagement in PISA 2003. París: OECD.

Sullivan, Alice (2001). "Cultural Capital and Educational Attainment». Sociology [en línea], 35 (4), 893-912. <http://dx.doi.org/10.1177/0038038501035004006>.

Trice, A. D. (1990). «Reliability of students' self-reports of scholastic aptitude scores: Data from juniors and seniors». Perceptual and Motor Skills, 71 (1), 290. $<$ http://dx.doi.org/10.2466/PMS.71.4.290-290>.

Teachman, Jay D. (1987). «Family Background, Educational Resources and Educational Attainment». American Sociological Review [en línea], 52, 548-557. $<$ http://dx.doi.org/10.2307/2095300>.

Zinovyeva, Natalia; Felgueroso, Florentino y Vázquez Vega, Pablo (2014). «Inmigration and student achievement in Spain: Evidence from PISA». SERIEs [en línea], 5 (1), 25-60.

$<$ http://dx.doi.org/10.1007/s13209-013-0101-7>. 


\section{Anexo}

Tabla A.1. Coeficientes estandarizados. Regresiones múltiples (MCO)

\begin{tabular}{|c|c|c|}
\hline & Variables & Nota global $(\beta)$ \\
\hline & \multicolumn{2}{|l|}{ Origen (Ref.: españoles de origen nativo) } \\
\hline & Europa occidental & $-0,087$ \\
\hline & América Latina & $-0,035$ \\
\hline & Marruecos & $-0,028$ \\
\hline & Otros APMED & $-0,008$ \\
\hline & Resto de inmigrantes & $-0,003$ \\
\hline & Sexo: mujeres (Ref.: hombres) & 0,113 \\
\hline & Edad & $-0,239$ \\
\hline & Curso: cuarto de ESO (Ref.: tercero de ESO) & 0,217 \\
\hline \multirow{4}{*}{ } & Estatus socioeconómico (ISEI) & 0,065 \\
\hline & Nivel educativo de los padres (Ref.: sin estudios / con estudios primarios) & \\
\hline & Estudios secundarios & 0,017 \\
\hline & Estudios universitarios & 0,043 \\
\hline \multirow{19}{*}{ 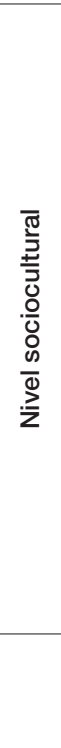 } & Recursos educativos en el hogar & \\
\hline & Sitio tranquilo & 0,071 \\
\hline & Ordenador & 0,053 \\
\hline & Diccionario & 0,048 \\
\hline & Calculadora & 0,062 \\
\hline & Más de 50 libros & 0,084 \\
\hline & Clases culturales extraescolares & \\
\hline & Música & 0,076 \\
\hline & Idiomas & 0,117 \\
\hline & Arte & 0,053 \\
\hline & Actividades culturales & \\
\hline & Ir al teatro & 0,013 \\
\hline & Tocar un instrumento musical & 0,043 \\
\hline & Ir a museos & 0,072 \\
\hline & Leer libros no relacionados con el IES & 0,013 \\
\hline & Afición por la lectura & 0,125 \\
\hline & Constante & 9,084 \\
\hline & $N$ & 1.291 \\
\hline & $\mathrm{R}^{2}$ & 0,247 \\
\hline
\end{tabular}

Fuente: Álvarez de Sotomayor (2011). 